“ (C) 2013 IEEE. Personal use of this material is permitted. Permission from IEEE must be obtained for all other uses, in any current or future media, including

reprinting/republishing this material for advertising or promotional purposes, creating new collective works, for resale or redistribution to servers or lists, or reuse of any copyrighted component of this work in other works." 


\title{
Feedforward Decoupling Control Method in Grid-interfaced Inverter
}

\author{
Dung H Pham, Gregory Hunter, Li Li and Jianguo Zhu \\ Centre for Electrical Machines and Power Electronics \\ Faculty of Engineering and Information Technology \\ University of Technology, Sydney, Australia \\ hung.d.pham@stutend.uts.edu.au
}

\begin{abstract}
Recently, microgrid has been studied and applied widely all over the world. More and more experimental microgrids are being connected to the utility grid. This paper presents an improvement in the real and reactive power control of three-phase grid-interfaced inverter for microgrid applications. Based on the traditional PI feedback current control, the desirable values of $P$ and $Q$ can be achieved by controlling the currents in $d-q$ stationary frame. Moreover, the feedforward control method also brings some advantages to the systems such as higher reliability and enhanced stability. One of the most important improvements is to decouple the real and reactive power, i.e. $P$ and $Q$ are controlled separately. In this paper, the controller with feedforward algorithm has been simulated and shows some promiscuous results.
\end{abstract}

Keywords-microgrid; three-phase; grid-interfaced inverter; decouple; feedforward

\section{INTRODUCTION}

Nowadays, as the traditional energy sources like fossil fuels are running out and causing some environmental problems, renewable energy resources have attracted more and more attention. Solar photovoltaic (PV) generates electricity in well over 100 countries and continues to be the fastest growing renewable source in the world. Between 2004 and 2009, grid connected PV capacity increased at an annual average rate of $60 \%$ and over this five-year-period, annual growth rates for cumulative wind power capacity averaged $27 \%$. The concept of microgrid, composed of renewable power generators, load, energy storage devices and distribution control unit, was introduced in early 2000s [1] and developed throughout the world in the last decade[2-7] as an effective means to integrate intermittent renewable power sources in the power grids.

In many microgrids, a three-phase inverter is implemented to transfer active and reactive power between the microgrid and the utility grid. The voltage source converter (VSC) with an output L-type or LCL-type filter is commonly used. The LCL-type filters, though superior in terms of filter size and weight; introduces undesirable high-frequency resonances in the output current. Passive damping of those resonances would cause power losses, whereas the active damping often requires measurement of multiple signals used in a complicated control method. In this paper, the L-type filter is used. The LCL-type filter will be studied in the future.

In general, the methods for three-phase grid-connected inverters are implemented in either stationary domain [8,9] or synchronous reference domain[10-13]. The stationary frame can avoid the coupling terms and also the possibility of controlling harmonics, but suffers from the higher order control, more complicated design, sensitivity of the design to the grid frequency [14], and digital implementation difficulties known for resonant controllers[15]. The great advantage of the synchronous reference method is in mapping the AC variables into DC quantities and thus, it is possible to employ simple PI controllers. A side effect of this transformation is, however, the introduction of mutual coupling terms into the model equations. Conventionally, input decoupling terms are used to decouple the active and reactive power control loops, and simple PI controllers are used.

The suppression of the injected grid current harmonics is an important aspect of the power quality issues [10]. IEEE STD 1547-2009 gives the limitation of the injected grid current harmonics.

The control of active and reactive power has been widely understood and applied in rectifiers, grid-connection inverters of PV fuel cells, and distributed power generation systems [1620]. This paper presents the grid-interfacing inverter for a new microgrid with a DC bus[21]. This inverter has these following tasks:

(a) To control the active and reactive power transfer between the microgrid and the utility grid.

(b) To ensure high quality of the injected power.

\section{POWER AND REACTIVE POWER CONTROL OF GRID- CONNECTED INVERTER IN MICROGRID}

\section{A. Model in the stationary frame and synchronous $d$-q frame}

Figs. 1 and 2 show the structure of the microgrid and its grid-interfaced inverter studied in this paper. Assume that under the normal condition, using the droop control method within the microgrid, the DC bus voltage of the microgrid can be described as a DC source. A standard three-phase voltage source inverter with an L filter connects the microgrid to the 


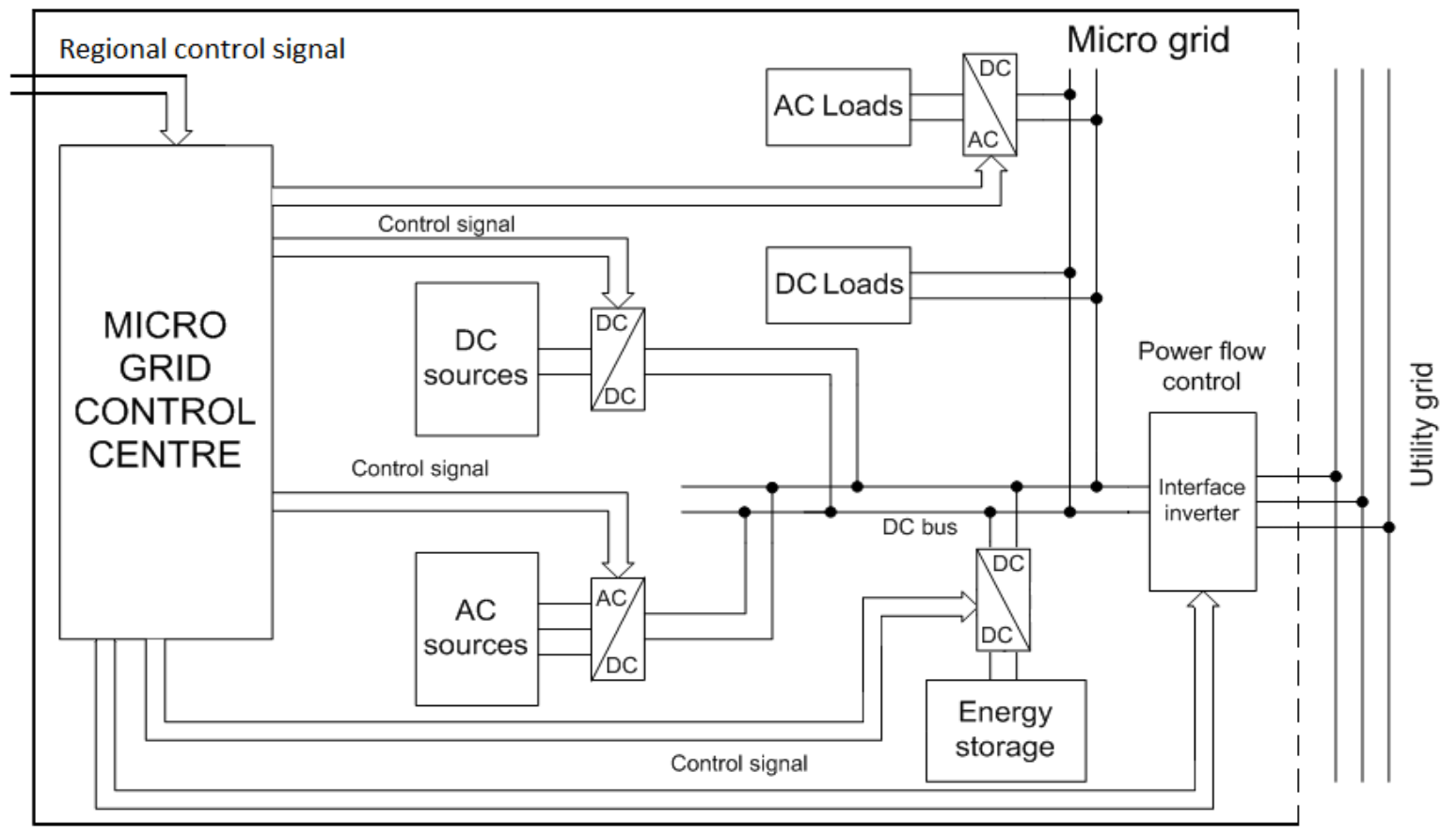

Fig.1. Structure of the proposed DC microgrid

utility grid, where $\mathrm{L}$ and $\mathrm{R}$ are the inductor and resistor, respectively. In this structure, the microgrid control centre is the most important part of the microgrid, as it will receive all the signals from regional control centre, conditions of power sources, loads and energy storage units. After that, when all the data is collected, the microgrid control centre will determine the operation of each power converter within the microgrid as well as the power and reactive power transfer with the utility grid through the grid-interfacing inverter to meet the load demands or satisfy the needs from the main grid.

According to Fig.2, the mathematical model in the stationary ABC frame of the three-phase grid-connected inverter is described as:

$$
\left\{\begin{array}{l}
V_{\text {out }_{a}}(t)=V_{\text {grid }_{a}}(t)+R i_{a}(t)+L \frac{d}{d t} i_{a}(t) \\
V_{\text {out }_{b}}(t)=V_{\text {grid }_{b}}(t)+R i_{b}(t)+L \frac{d}{d t} i_{b}(t) \\
V_{\text {out }_{c}}(t)=V_{\text {grid }_{c}}(t)+R i_{c}(t)+L \frac{d}{d t} i_{c}(t)
\end{array}\right.
$$

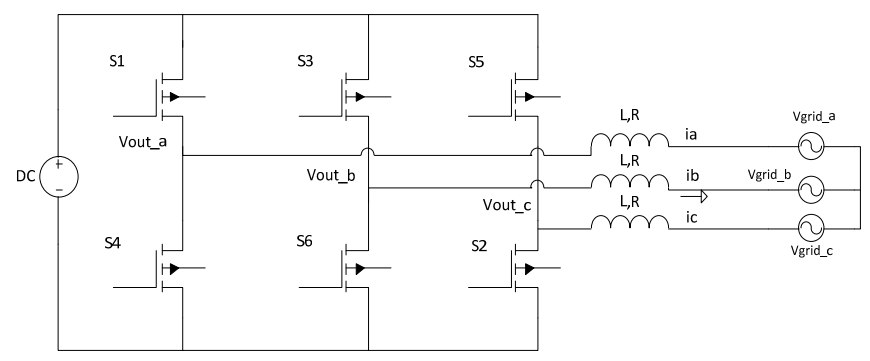

Fig.2. Simplified L-type filter grid-connected inverter or

$\left[V_{\text {out }_{a b c}}(t)\right]=\left[V_{\text {grid }_{a b c}}(t)\right]+R\left[i_{a b c}(t)\right]+L \frac{\mathrm{d}}{\mathrm{dt}}\left[i_{a b c}(t)\right]$

where

$\left[V_{\text {out }_{\text {abc }}}(t)\right]=\left[V_{\text {out }_{a}}(t), V_{\text {out }_{b}}(t), V_{\text {out }_{c}}(t)\right]^{T}$ is the voltage vectors of three inverter legs,

$\left[V_{\operatorname{grid}_{a b c}}(t)\right]=\left[V_{\text {grid }_{a}}(t), V_{\text {grid }_{b}}(t), V_{\text {grid }_{c}}(t)\right]^{T}$ the grid voltage vectors, and

$\left[i_{a b c}(t)\right]=\left[i_{a}(t), i_{b}(t), i_{c}(t)\right]^{T}$ the inverter-side inductor currents.

Any three-phase variables can be transformed from the three-phase stationary reference frame to a two-phase rotating reference frame by the constant power Park transform. The coordinate transform matrix is

$$
\left[T_{A B C \rightarrow d q 0}\right]=\sqrt{\frac{2}{3}}\left[\begin{array}{ccc}
\cos \theta & \cos \left(\theta-\frac{2 \pi}{3}\right) & \cos \left(\theta+\frac{2 \pi}{3}\right) \\
-\sin \theta & -\sin \left(\theta-\frac{2 \pi}{3}\right) & -\sin \left(\theta+\frac{2 \pi}{3}\right) \\
\frac{1}{\sqrt{2}} & \frac{1}{\sqrt{2}} & \frac{1}{\sqrt{2}}
\end{array}\right]
$$

where $\theta=\omega t+\delta$ is the angle between the rotating and fixed coordinate system at each time $t$, and $\delta$ is the initial phase shift of the voltage. Applying this constant power Park transformation to (2), the mathematic model of the interfacinginverter in the $d-q$ frame can be expressed as

$$
\begin{aligned}
& {\left[V_{\text {out }_{d q}}(t)\right]=\left[V_{\text {grid }_{d q}}(t)\right]+R\left[i_{d q}(t)\right]} \\
& +\omega L\left[\begin{array}{cc}
0 & -1 \\
1 & 0
\end{array}\right] \cdot\left[i_{d q}(t)\right]+L \frac{d}{d t}\left[i_{d q}(t)\right]
\end{aligned}
$$




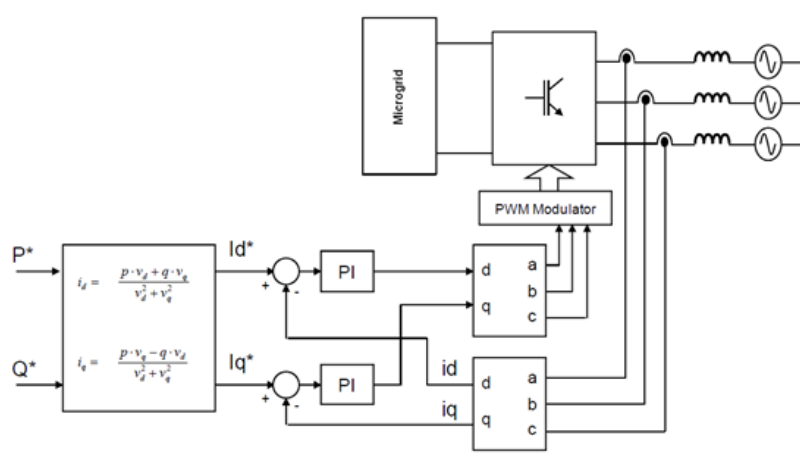

Fig.3. Active and reactive power control by regulating current in synchronous $d-q$ frame

$$
\left\{\begin{array}{l}
V_{\text {out }_{d}}=V_{\text {grid }_{d}}+R i_{d}+L \frac{d}{d t} i_{d}-\omega L i_{q} \\
V_{\text {out_q }}=V_{\text {grid_q }}+R i_{q}+L \frac{d}{d t} i_{q}+\omega L i_{d}
\end{array}\right.
$$

\section{B. Active and reactive power control}

The active and reactive power then can be controlled by controlling the current in the synchronous rotating $d$ - $q$ frame as described in Fig.3.

The synchronous $d-q$ frame control has the particular advantage of controlling the active and reactive current directly, which is very convenient to control the active and reactive power. The active and reactive power for a balanced three-phase system can be written in the synchronous $d-q$ frame as follows:

$$
\left\{\begin{array}{l}
P=V_{d} \cdot I_{d}+V_{q} I_{q} \\
Q=V_{d} I_{q}-V_{q} I_{d}
\end{array}\right.
$$

Therefore, with each given $P$ and $Q, I_{d}$ and $I_{q}$ can be obtained as

$$
\left\{\begin{array}{l}
I_{d}=\frac{P V_{d}-Q V_{q}}{V_{d}^{2}+V_{q}^{2}} \\
I_{q}=\frac{P V_{d}+Q V_{q}}{V_{d}^{2}+V_{q}^{2}}
\end{array}\right.
$$

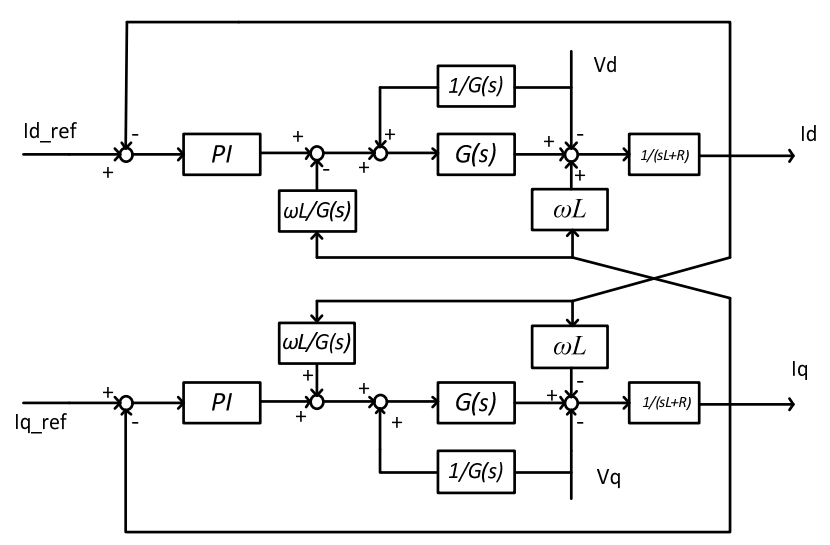

Fig.5. Feedforward scheme for the synchronous d-q frame

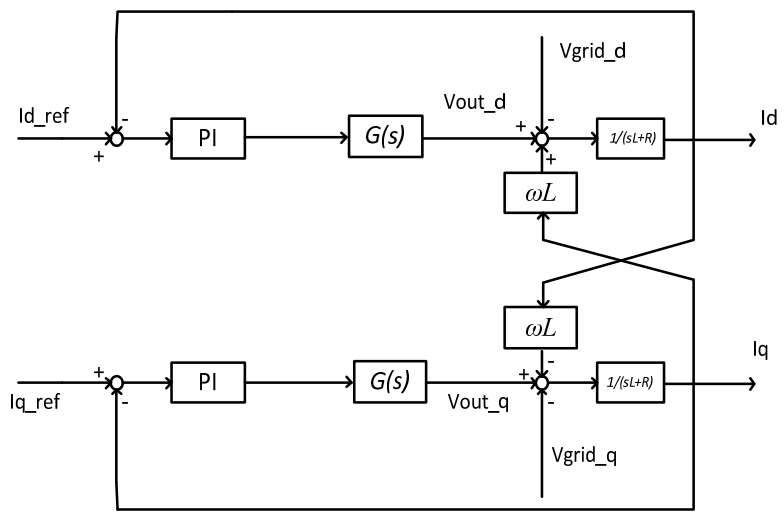

Fig.4. Block diagram of feedback PI inductor current control

Equation (5) indicates that the feedback of inductor currents can be used for PI control as described in Fig.4. With $I_{d}$ and $I_{q}$ control, we can control the real and reactive power transfer between the microgrid and the main grid.

With the single-loop feedback PI control, we have a multivariable system with double input and double outputs. The distinctive point of this multi-variable system is the interaction between the variables, which is shown by the decoupling terms of $\omega L$ in (5). The coupling terms will affect the stabilization, static and dynamic characteristics of the system. Therefore, this paper will present some decoupling method to control the real and reactive power independently.

\section{DIFFERENT DECOUPLING CURRENT CONTROL SCHEME FOR THE SYNCHRONOUS D-Q FRAME}

\section{A. State feedback scheme for the synchronous d-q frame}

Fig.5 shows the addition paths, which can eliminate the effect of the grid voltages to the injected current. The cross effect between the $d$ and $q$ axis components will also be removed. However, in a real time circuit, there is always a difference between the dynamic responses and the regulated currents, which makes this method not ideal.

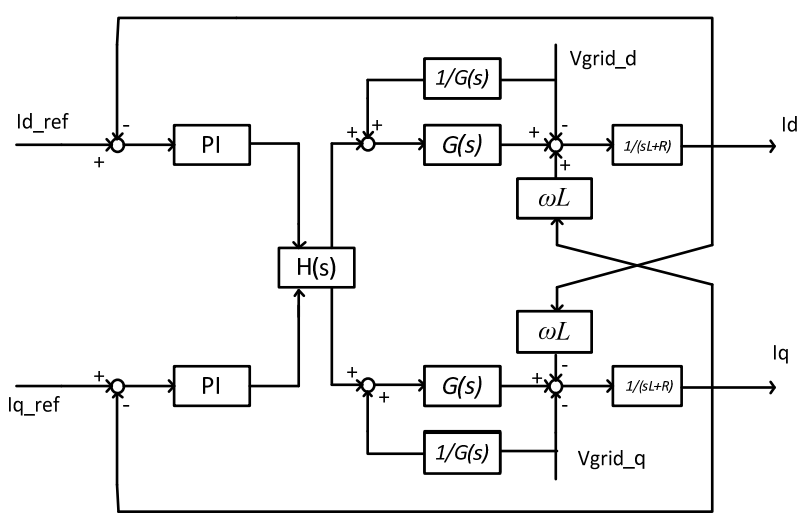

Fig.6. The block diagram of series feedforward in d-q frame 


\section{B. Series feedforward scheme for the synchronous $d$-q frame}

Fig.6 describes the idea of series feedforward, which adds a series block $H(s)$ behind the PI current controller to decouple completely the $d$ and $q$ axis components. For this multivariable control system, the "relative gain" concept proposed in [20] can be applied to scale the degree of coupling and decoupling. Suppose $y$ is a row vector containing all included variables $y_{i}$ and $u$ is a row vector containing all independent variables $u_{j}$, the "relative gain" between $u_{j}$ and $y_{i}$ can be defined as

$$
\lambda_{i j}=\frac{\left.\frac{\partial y_{i}}{\partial u_{j}}\right|_{u}}{\left.\frac{\partial y_{i}}{\partial u_{j}}\right|_{y}}
$$

If $\lambda_{i j}=1$, it means that there is no interaction between the channel from $u_{j}$ to $y_{i}$ and the other channels. Whether the other channels are closed or not, the open-loop gain of the channel from $u_{j}$ to $y_{i}$ will not be affected. If $\lambda_{i j}=0$, it means that $y_{i}$ is unaffected by $u_{j}$. The greater $\lambda_{i j} \gg 1$, the stronger is the coupling between the channels. In Fig.6, let

$$
[H(s)]=\left[\begin{array}{ll}
H_{11}(s) & H_{12}(s) \\
H_{21}(s) & H_{22}(s)
\end{array}\right]
$$

From (5) it can be given that

$$
\left[\begin{array}{cc}
R+s L & -\omega L \\
\omega L & R+s L
\end{array}\right]\left[\begin{array}{l}
i_{d} \\
i_{q}
\end{array}\right]=\left[\begin{array}{ll}
H_{11}(s) & H_{12}(s) \\
H_{21}(s) & H_{22}(s)
\end{array}\right]\left[\begin{array}{l}
V_{\text {out }_{d}} \\
V_{\text {out }_{q}}
\end{array}\right]
$$

The relative gain between two input variables $i_{d}, i_{q}$ and two output $V_{\text {out }_{d}}, V_{\text {out }_{q}}$ will be shown in (11) below

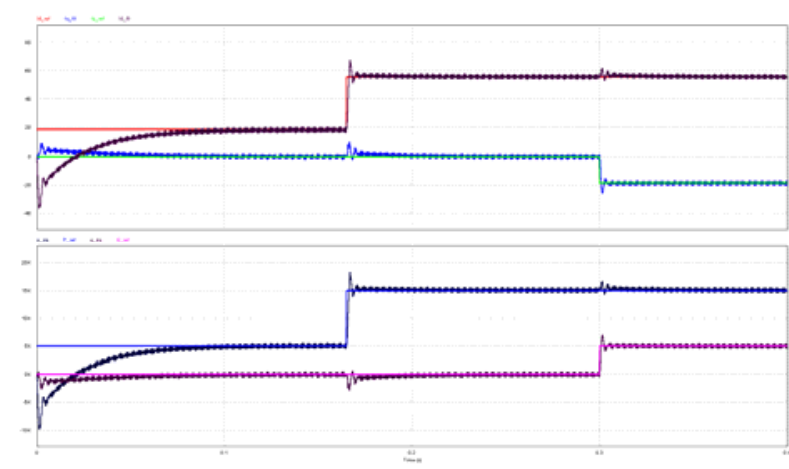

(a)

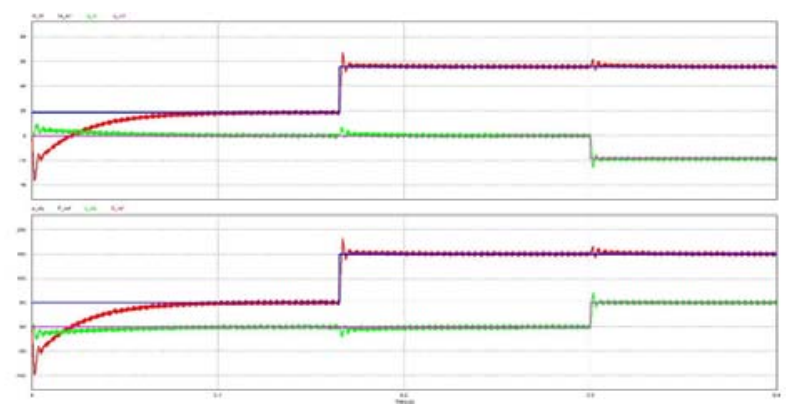

(b)

Fig.6.Power and reactive power control with feedback and feedforward (a) feedback current control of Id and Iq (b) feedforward current control of Id and Iq

$$
\lambda_{11}=\lambda_{22}=\frac{\left\{(R+s L) H_{12}+\omega L H_{21}\right\}\left\{-\omega L H_{21}+(R+s L) H_{22}\right\}}{\left\{(R+s L) H_{12}+\omega L H_{21}\right\}\left\{-\omega L H_{21}+(R+s L) H_{22}\right\}+\left\{(R+s L) H_{12}+\omega L H_{22}\right\}\left\{-\omega L H_{11}+(R+s L) H_{21}\right\}}
$$

When $\lambda_{11}=\lambda_{22}=1$, one obtains

$$
\left\{(R+s L) H_{12}+\omega L H_{22}\right\}\left\{-\omega L H_{11}+(R+s L) H_{21}\right\}=0
$$

Therefore, the interaction between the $d$ and $q$ axes can be decoupled completely, if one chooses

$$
\left\{\begin{array}{c}
H_{11}(s)=H_{22}(s)=1 \\
H_{12}(s)=\frac{-\omega L}{s L+R} \\
H_{21}(s)=\frac{\omega L}{s L+R}
\end{array}\right.
$$

\section{SimULATION RESUlT}

The system is simulated in the PSIM software, the DC bus voltage is $400 \mathrm{~V}$. The grid voltage is $220 \mathrm{Vrms}$ line-line, $f=$ $50 \mathrm{~Hz}$. $P=5000 \mathrm{~W}$ at $\mathrm{t}=0 \mathrm{~s}, 10000 \mathrm{~W}$ at $\mathrm{t}=0.165 \mathrm{~s}$. $Q=0 \mathrm{VAR}$ at $\mathrm{t}=0 \mathrm{~s}$, and 5000VAR at $\mathrm{t}=0.3 \mathrm{~s}$.

As can be seen in Fig.6(a), with the input are $P$ and $Q$, the synchronous $d-q$ frame current can be controlled to achieve the desired active and reactive power transfer between microgrid and utility grid. However, when there are changes in active power and reactive power set point, there are also fluctuations in the other variable, which mean there is cross effect between them. Fig.6(b) shows the result of the cross-coupling

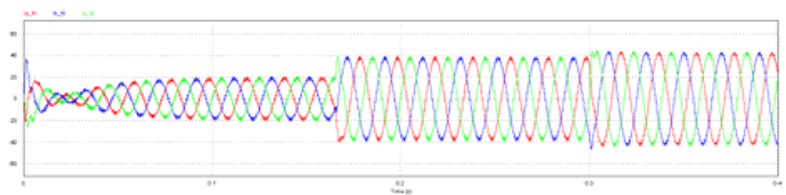

Fig.7.Output current of three-phase interfaced inverter

feedforward. The cross effect between the $d-q$ axes has been reduced significantly but cannot be eliminated perfectly. It can be explained that when building the mathematical model of the system, the frequency is assumed constant, the balance between all phases is secured, and then all the transformation is exactly. However, when there is a change in every voltage of the system, not all the assumption is right anymore, therefore the feedforward has the perfect result.

This result means that the decoupling control method cannot be implied completely in term of dynamic performance and still can be improved.

\section{CONCLUSION}

This report presents a new microgrid structure with the grid-connected inverter, which can control the active and reactive power transfer between microgrid and utility grid. 
With feedforward schemes, the cross effect between active and reactive power has been greatly reduced, and the injected grid currents caused by the grid voltages are small.

Future work will be the study on feedforward with LCLtype filter and other decoupling control methods

\section{REFERENCES}

[1] R. H. Lasseter, "MicroGrids," in Power Engineering Society Winter Meeting, 2002. IEEE, 2002, pp. 305-308 vol.1.

[2] D. Guezgouz, D. E. Chariag, Y. Raingeaud, and J. C. Le Bunetel, "Modeling of Electromagnetic Interference and PLC Transmission for Loads Shedding in a Microgrid," Power Electronics, IEEE Transactions on, vol. 26, pp. 747-754, 2011.

[3] W. Fei, J. L. Duarte, and M. A. M. Hendrix, "Grid-Interfacing Converter Systems With Enhanced Voltage Quality for Microgrid Application;Concept and Implementation," Power Electronics, IEEE Transactions on, vol. 26, pp. 3501-3513, 2011.

[4] S. Bolognani and S. Zampieri, "Distributed control for optimal reactive power compensation in smart microgrids," in Decision and Control and European Control Conference (CDC-ECC), 2011 50th IEEE Conference on, 2011, pp. 6630-6635.

[5] G. Mine, R. Borer, F. Kupzog, and H. Nishi, "Construction method of dynamic microgrid by using optimized grouping method," in Industrial Informatics (INDIN), 2010 8th IEEE International Conference on, 2010, pp. 780-785.

[6] L. Xiong, W. Peng, and L. Poh Chiang, "A Hybrid AC/DC Microgrid and Its Coordination Control," Smart Grid, IEEE Transactions on, vol. 2, pp. 278-286, 2011.

[7] J. M. Guerrero, J. C. Vasquez, J. Matas, L. G. de Vicuna, and M. Castilla, "Hierarchical Control of Droop-Controlled AC and DC Microgrids;A General Approach Toward Standardization," Industrial Electronics, IEEE Transactions on, vol. 58, pp. 158-172, 2011.

[8] I. J. Gabe, V. F. Montagner, and H. Pinheiro, "Design and Implementation of a Robust Current Controller for VSI Connected to the Grid Through an LCL Filter," Power Electronics, IEEE Transactions on, vol. 24, pp. 1444-1452, 2009.

[9] L. Poh Chiang and D. G. Holmes, "Analysis of multiloop control strategies for LC/CL/LCL-filtered voltage-source and current-source inverters," Industry Applications, IEEE Transactions on, vol. 41, pp. 644-654, 2005.
[10] F. Blaabjerg, R. Teodorescu, M. Liserre, and A. V. Timbus, "Overview of Control and Grid Synchronization for Distributed Power Generation Systems," Industrial Electronics, IEEE Transactions on, vol. 53, pp. 1398-1409, 2006.

[11] M. Liserre, R. Teodorescu, and F. Blaabjerg, "Multiple harmonics control for three-phase grid converter systems with the use of PI-RES current controller in a rotating frame," Power Electronics, IEEE Transactions on, vol. 21, pp. 836-841, 2006.

[12] W. Eric and P. W. Lehn, "Digital Current Control of a Voltage Source Converter With Active Damping of LCL Resonance," Power Electronics, IEEE Transactions on, vol. 21, pp. 1364-1373, 2006.

[13] M. Malinowski and S. Bernet, "A Simple Voltage Sensorless Active Damping Scheme for Three-Phase PWM Converters With an LCL Filter," Industrial Electronics, IEEE Transactions on, vol. 55, pp. 18761880, 2008.

[14] A. V. Timbus, M. Ciobotaru, R. Teodorescu, and F. Blaabjerg, "Adaptive resonant controller for grid-connected converters in distributed power generation systems," in Applied Power Electronics Conference and Exposition, 2006. APEC '06. Twenty-First Annual IEEE, 2006, p. 6 pp.

[15] R. Teodorescu, F. Blaabjerg, M. Liserre, and P. C. Loh, "Proportionalresonant controllers and filters for grid-connected voltage-source converters," Electric Power Applications, IEE Proceedings -, vol. 153, pp. 750-762, 2006.

[16] S. A. Azmi, G. P. Adam, K. H. Ahmed, S. J. Finney, and B. W. Williams, "Grid Interfacing of Multimegawatt Photovoltaic Inverters," Power Electronics, IEEE Transactions on, vol. 28, pp. 2770-2784, 2013.

[17] Y. Bo, L. Wuhua, Z. Yi, and H. Xiangning, "Design and Analysis of a Grid-Connected Photovoltaic Power System," Power Electronics, IEEE Transactions on, vol. 25, pp. 992-1000, 2010.

[18] R. Majumder, "Reactive Power Compensation in Single-Phase Operation of Microgrid," Industrial Electronics, IEEE Transactions on, vol. 60, pp. 1403-1416, 2013.

[19] L. Hongbo, Z. Kai, Z. Hui, F. Shengfang, and X. Jian, "Active Power Decoupling for High-Power Single-Phase PWM Rectifiers," Power Electronics, IEEE Transactions on, vol. 28, pp. 1308-1319, 2013.

[20] D. Ke, L. Ping, K. Yong, and C. Jian, "Decoupling current control for voltage source converter in synchronous roating frame," in Power Electronics and Drive Systems, 2001. Proceedings., 2001 4th IEEE International Conference on, 2001, pp. 39-43 vol.1.

[21] D. H. Pham, G. Hunter, L. Li, and Z. Jianguo, "Microgrid topology for different applications in Vietnam," in Universities Power Engineering Conference (AUPEC), 2012 22nd Australasian, 2012, pp. 1-6. 